\title{
Genetically Modified Sugarcane Intercropping Soybean Impact on Rhizosphere Bacterial Communities and Co-occurrence Patterns
}

OPEN ACCESS

Edited by:

Paulo Arruda,

State University of Campinas, Brazil

Reviewed by:

Wagner Rodrigo De Souza, Brazilian Agricultural Research Corporation (EMBRAPA), Brazil

Manoj Kumar Solanki, University of Silesia in Katowice,

Poland

*Correspondence:

Yue Liu

Liuyue644@gmail.com

Ziting Wang

zitingwang@gxu.edu.cn

${ }^{\dagger}$ These authors have contributed equally to this work and share first authorship

Specialty section:

This article was submitted to Microbe and Virus Interactions with

Plants,

a section of the journal

Frontiers in Microbiology

Received: 19 July 2021 Accepted: 09 November 2021 Published: 09 December 2021

Citation:

Wei B, Zhang J, Wen R, Chen T, Xia N, Liu Y and Wang Z (2021)

Genetically Modified Sugarcane Intercropping Soybean Impact on Rhizosphere Bacterial Communities

and Co-occurrence Patterns.

Front. Microbiol. 12:742341. do: 10.3389/fmicb.2021.742341

\author{
Beilei Wei ${ }^{1,2,3 \dagger}$, Jinlian Zhang ${ }^{1,47}$, Rushuang Wen ${ }^{2}$, Tingsu Chen ${ }^{4}$, Ningshao Xia', \\ Yue Liu' ${ }^{2,3 *}$ and Ziting Wang ${ }^{2,3 *}$
}

' State Key Laboratory of Molecular Vaccinology and Molecular Diagnostics, National Institute of Diagnostics and Vaccine Development in Infectious Diseases, School of Life Sciences, School of Public Health, Xiamen University, Xiamen, China, ${ }^{2}$ College of Agronomy, Guangxi University, Nanning, China, ${ }^{3}$ Guangxi Key Laboratory of Sugarcane Biology, Nanning, China, ${ }^{4}$ Microbiology Research Institute, Guangxi Academy of Agricultural Sciences, Nanning, China

Strategies involving genes in the dehydration-responsive element binding (DREB) family, which participates in drought stress regulation, and intercropping with legumes are becoming prominent options in promoting sustainable sugarcane cultivation. An increasing number of studies focusing on root interactions in intercropping systems, particularly involving transgenic crops, are being conducted to better understand and thus, harness beneficial soil microbes to enhance plant growth. We designed experiments to investigate the characteristics of two intercropping patterns, soybean with wild-type (WT) sugarcane and soybean with genetically modified (GM) Ea-DREB2Boverexpressing sugarcane, to assess the response of the rhizosphere microbiota to the different cropping patterns. Bacterial diversity in the rhizosphere microbial community differed between the two intercropping pattens. In addition, the biomass of GM sugarcane that intercropped with soybean was significantly improved compared with WT sugarcane, and the aboveground biomass and root biomass of GM soybean intercropping sugarcane increased by 49.15 and $46.03 \%$ compared with monoculture. Furthermore, a beneficial rhizosphere environment for the growth of Actinobacteria was established in the systems intercropped with GM sugarcane. Improving the production mode of crops by genetic modification is a key strategy to improving crop yields and provides new opportunities to further investigate the effects of intercropping on plant roots and soil microbiota. Thus, this study provides a basis for selecting suitable sugarcane-soybean intercropping patterns and a theoretical foundation for a sustainable sugarcane production.

Keywords: intercropping, transgenic crops, rhizosphere microbial environment, interaction, sugarcane

\section{INTRODUCTION}

Sugarcane (Saccharum officinarum L.) is a tall perennial grass that stores high concentrations of sucrose in its stems. It is cultivated in over 80 countries in the tropics, semi-subtropics, and subtropics (Tew and Cobill, 2008). As a C4 plant, sugarcane yields a greater biomass than maize, silvergrass (Miscanthus), and switchgrass (Panicum virgatum) (Heaton et al., 2008). Owing to this high biomass yield, sugarcane cultivation competes less for land designated for food crops and it is the first choice for high-yielding sugar crops (Peskett et al., 2007). However, irregular perennial 
precipitation and incomplete irrigation facilities in sugarcane regions have made drought one of the main factors restricting sugarcane yield increase; thus, breeding drought-resistant sugarcane varieties has become an urgent task (Santos et al., 2019). Drought resistance itself is a complex trait controlled by many genes (Budak et al., 2015), and their identification will be of great significance for the development and subsequent cultivation of drought-resistant sugarcane varieties (Zhao et al., 2020c). Members of the dehydration-responsive element binding $(D R E B)$ subfamily of genes play key roles in plant stress responses to low temperatures, drought, and high salinity (Zhou Y. et al., 2019). Ea-DREB2B, a member of the DREB2 family that was cloned from the hardy sugarcane Saccharum arundinaceum, plays a critical role in enhancing the tolerance of plants to drought and salinity (Ali et al., 2017). Ea-DREB2B-modified transgenic crops have been demonstrated to have improved drought tolerance by altering their plant hormone metabolism and root growth (Paul and Roychoudhury, 2018). It was also speculated that the expression of $E a-D R E B 2 B$ in the roots of transgenic sugarcane affects the production of root exudates and consequently, alters the bacterial community structure in crop rhizosphere (Zhao et al., 2020a).

Intercropping is a practice of planting two or more different crop varieties at the same time in different combinations in the same area of land to improve crop yields; it is commonly implemented for co-cultivation of soybean and gramineous crops (Singh et al., 2018). Intercropping improves the mobilization and absorption of potassium, phosphorus, and micronutrients through rhizosphere interactions, improved soil microecology, and increased microbial counts and enzyme activity in the soil, which are critical to increase crop yield (Zhou Q. et al., 2019). Wang et al. (2020) indicated that soybean and sugarcane intercropping, complemented with reduced nitrogen application could improve sugarcane yield and reduce carbon footprint in China. This practice has been widely used to reduce nitrogen leaching and stabilize yield (Luo et al., 2016; Lian et al., 2018). In addition, previous studies have demonstrated that soybean has a higher impact on biological and chemical properties of soil in intercropping systems compared with other legumes, such as peanuts, thus, ameliorating field ecological conditions and enhancing soil fertility, which favor sugarcane growth (Solanki et al., 2017; Du et al., 2018). However, the impact of intercropping soybean with $D R E B$ gene-modified crops particularly with drought-tolerant sugarcane varieties on nitrogen uptake remains unclear.

Rhizosphere microbes are essential components of the plant and soil environment and provide valuable ecosystem services. These microbes are associated with numerous important biochemical reactions that affect plant growth and metabolism (Souza et al., 2015). The integration of transgenic plants may have either intended or unintended effects on soil microbial communities and functions (DeBruyn et al., 2017; Wei et al., 2020). The interaction between genetically modified (GM) crops and rhizosphere microbes is mainly associated with the production of root exudates and tiller or leaf degradation (Khan et al., 2017). Accordingly, alterations in the enzymatic activities of rhizosphere microbes have been identified (Chen et al., 2018).
Previous studies have indicated that genetic modification can change the rhizosphere bacterial community of plants. Compared with the wild-type (WT) sugarcane, the diversity and composition of bacterial rhizosphere community of $E a-D R E B 2 B$ transgenic sugarcane is significantly different, which has been contributed to the root exudates of the transgenic plants (Zhao et al., 2020a). However, to date, no studies have determined whether the intercropping of transgenic crops with soybean modifies the microbiome composition of the rhizoplane and rhizosphere of soybean.

Metagenomic analysis is used to construct metagenomic libraries by directly extracting all microbial DNA from soil samples and using genomics research strategies to study the genetic composition and community functions of all microorganisms contained in environmental samples (Riesenfeld et al., 2004). Amplicon sequencing and whole genome sequencing are the most widely used in metagenomic analysis (Petrosino et al., 2009). Amplicon sequencing was used to analyze the composition and abundance of microbial communities in environmental samples by using PCR to amplify marker genes shared by microorganisms (Schöler et al., 2017). Commonly used studies include the composition of bacterial archaea based on 16S rRNA gene sequencing, the composition of eukaryotes such as fungi and protozoa studied by ITS/18S sequencing, and the nitrogen fixation related microbial communities studied by nifH gene sequencing (Izquierdo and Nüsslein, 2006; Li et al., 2011; Zhou et al., 2017). The advantages of amplicon sequencing are simple, rapid, low cost and mature analytical methods, which are favored by many microbial researchers. Illumina Hiseq2,500 and MiSeq are commonly used sequencing platforms (El-Metwally et al., 2014). At present, the main analysis processes of ampland data analysis have been quite mature, including data preprocessing (combination or splicing of double-ended sequences, data quality control, chimera removal), OTU sequence clustering, $\alpha$ diversity analysis, $\beta$ diversity analysis, etc. With the continuous development of sequencing technology, more and more microbial sequence data will be generated. How to efficiently and quickly analyze data becomes particularly important. Under this demand, amplicon analysis platforms emerged at the historic moment. Currently, the three mainstream analysis platforms are Mothur (Schloss et al., 2009), QIIME (Caporaso et al., 2010), and USEARCH (Edgar, 2010). Mothur is a bioinformatics software with a very good architecture, integrating a large number of tools and modules, and standardizing the input and output. It can be used for distance calculation and diversity calculation, which is very suitable for the study of microbial ecology and population structure (Beck et al., 2015). USEARCH integrates many classical sequence analysis algorithms, most of which start with $U$, such as UCLUST sequence clustering algorithm, UPARSE algorithm, UNOISE sequence quality control algorithm and UCHIME removal algorithm. At present, USEARCH software has related commands in sequence quality control, chimeric removal, sequence search, OTU clustering and other processes, which are widely used (Prodan et al., 2020).

In this study, we conducted polymerase chain reaction (PCR) and high-throughput sequencing analyses to characterize 
the rhizosphere microbial communities in soybean fields intercropped with WT and GM sugarcane. We hypothesized that intercropping of GM sugarcane and soybean would affect the rhizosphere ecology and promote crop growth through changes in the rhizosphere microbial community structure instigated by GM sugarcane. Specifically, we aimed to: (1) determine whether the DREB-modified sugarcane and the WT sugarcane have different effects when intercropped with soybean, (2) establish the effect of GM sugarcane and soybean intercropping on the rhizosphere environment, and (3) characterize the relationship between the changes in the rhizosphere bacterial community and root growth. We believe that our study will provide a new idea for the design of planting pattern of sugarcane, that is, when interplanting with soybean, the choice of GM sugarcane interplanting is of positive significance to the formation of good soil environment.

\section{MATERIALS AND METHODS}

\section{Plants and Field Experimental Design}

This study was conducted in the forage breeding ground of Guangxi University located in Fusui, China $\left(22^{\circ} 17^{\prime} 0.01^{\prime \prime} \mathrm{N}\right.$, $\left.108^{\circ} 06^{\prime} 0.01^{\prime \prime} \mathrm{E}\right)$. The experimental field was established on a sugarcane continuous cropping field. The soil was of lateritic red earth, with total nitrogen $0.093 \%$, total phosphorus $0.024 \%$, total potassium $0.500 \%$, available nitrogen $70 \mathrm{mg} \mathrm{kg}^{-1}$, available phosphorus $10 \mathrm{mg} \mathrm{kg}^{-1}$, available potassium $286 \mathrm{mg} \mathrm{kg}^{-1}$, organic matter $8.90 \mathrm{~g} \mathrm{~kg}^{-1}$, and $\mathrm{pH} 8.33$ in the topsoil.

GN18 modified with a DREB gene (GM sugarcane) and FN95-1702 (WT sugarcane) were used as the two sugarcane cultivars in this experiment, and a local widely planted soybean cultivar, GUIZAO2, was used. The GN18 sugarcane cultivar was generated from FN95-1702 by transforming the inducible promoter rd29A into sugarcane callus via particle bombardment to overexpress Ea-DREB2B (Huaizhu et al., 2004). Five planting modes were designed: monocropped FN95-1702 (WT) sugarcane, monocropped GN18 (GM) sugarcane, monocropped GUIZAO2 soybean, FN95-1702 sugarcane intercropped with GUIZAO2 soybean, and GN18 sugarcane intercropped with GUIZAO2 soybean. All experiments were conducted in triplicates in each plot.

In the sugarcane-soybean intercropping and sugarcane monocropping systems, eight sugarcane rows, $8 \mathrm{~m}$ in length were planted at $1.2 \mathrm{~m}$ spacing and two rows of soybean were planted between sugarcane rows, with $0.4 \mathrm{~m}$ row spacing and $0.2 \mathrm{~m}$ plant spacing. Soybean monocropping plot consisted of 20 rows with a length of $8 \mathrm{~m}$ and row spacing of $0.4 \mathrm{~m}$. The five cropping systems were established on single plots, each with an area of $67.2 \mathrm{~m}^{2}$. We made Figure 1A to understand our experimental setup. Sugarcane was planted in March 2018, and soybean was planted $15 \mathrm{~d}$ after sugarcane plantation. Sugarcane stem segments and soybean seeds were soaked in $3 \% \mathrm{H}_{2} \mathrm{O}_{2}$ to disinfect their surfaces, and then rinsed thrice with deionized water before planting and sowing (Mahakham et al., 2017). After 45 days, whole sugarcane and soybean plants were collected along with the rhizosphere.

\section{Crop Sample Collection and Determination of Biomass}

Crop samples were randomly collected from the sugarcane mono-cropping plot (hereafter referred to as Mono-Sug), soybean monocropping plot (Mono-Soy), and sugarcanesoybean intercropping plot (Inter-Sug and Inter-Soy), sugarcane samples in soybean sugarcane intercropping are called Inter-Sug, including plant samples and rhizosphere soil samples; similarly, soybean samples in soybean and sugarcane intercropping are called Inter-Soy. Six plants were sampled per experimental plot of each treatment. The aboveground and underground parts of sugarcane and soybean were cleaned and their dry weight was determined by drying in the oven (Cui et al., 2018).

\section{Soil Sample Collection and Physicochemical Analysis}

The samples of soil were collected from the sugarcane rhizosphere in the Mono-Sug plots, soybean rhizosphere in the Mono-Soy plots, and sugarcane rhizosphere and soybean roots in the Inter-Sug and Inter-Soy plots, respectively. The roots were gently shaken to disengage the loosely attached soil on the root, and the soil thereafter attached to the root surface was defined as rhizosphere soil. This rhizosphere soil was removed by brushing with a sterilized brush and collected in a sterile bag. Collected rhizosphere soil sample from the same place was used as a composite sample. A $2 \mathrm{~mm}$ sieve was used to remove impurities, including plant residues and stones, from the soil samples and the resultant samples were divided into two portions, one for environmental factor determination and the other for DNA extraction. Later, the samples were stored at $-80{ }^{\circ} \mathrm{C}$ until further use. Available phosphorus (AP) and soil organic carbon (SOC) were determined following the methodologies mentioned by Jackson (1969) and Soon and Abboud (1991), respectively, and total nitrogen (TN) was determined using a semimicro Kjeldahl method (Bremner and Tabatabai, 1972).

\section{DNA Extraction, Amplicon Generation, and High-Throughput Sequencing}

DNA was extracted from $1 \mathrm{~g}$ soil samples using a DNA extraction kit (Omega Bio-Tek, Inc., Norcross, GA, United States). NanoDrop One spectrophotometer (Thermo Fisher Scientific, Waltham, MA, United States) was used to measure the DNA concentration and purity. A partial sequence of the 16S rRNA gene was amplified using a specific primer pair (338F-806R, F: ACTCCTACGGGAGGCAGCAG; R: GGACTACHVGGGTWTCTAAT) (Sun et al., 2020) that contained a 12 bp barcode; the primer pair was synthesized by Sangon (Sangon biotech, Shanghai, China). PCR reaction mixtures, containing $25 \mu \mathrm{L}$ of $2 \times$ Premix Taq (Sangon biotech, Shanghai, China), $2 \mu \mathrm{L}$ of each primer $(0.4 \mu \mathrm{M})$, and $1 \mu \mathrm{L}$ of DNA template $\left(20 \mathrm{ng} \mu \mathrm{L}^{-1}\right)$ in a total volume of $50 \mu \mathrm{L}$, were amplified by thermocycling under the following conditions: 4 min at $94^{\circ} \mathrm{C}$ for initial denaturation, followed by 35 cycles of $30 \mathrm{~s}$ denaturation at $94^{\circ} \mathrm{C}, 30 \mathrm{~s}$ annealing at $60^{\circ} \mathrm{C}$, and extension at $72^{\circ} \mathrm{C}$ for $30 \mathrm{~s}$, and final extension at $72^{\circ} \mathrm{C}$ for 10 min. Amplification was carried out in a thermocycler 
A

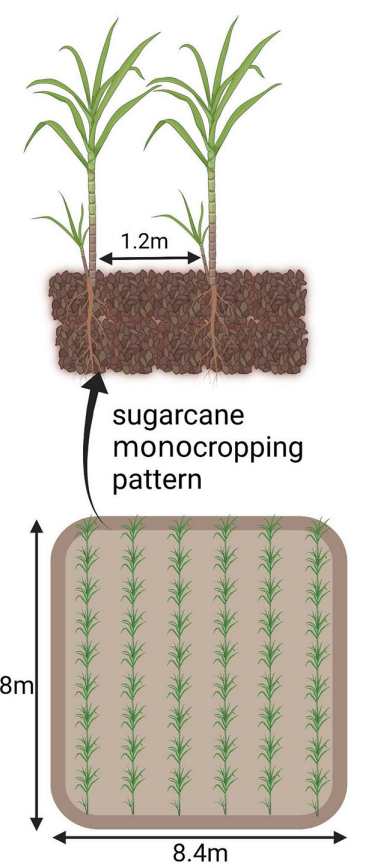

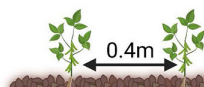
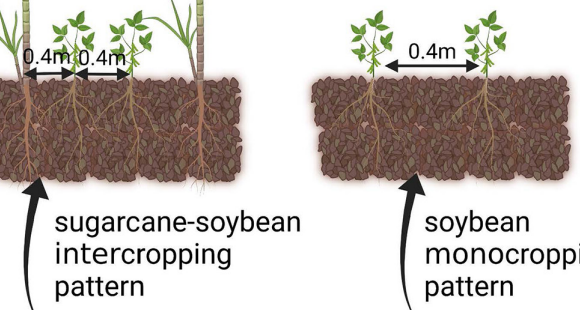

soybean monocropping pattern
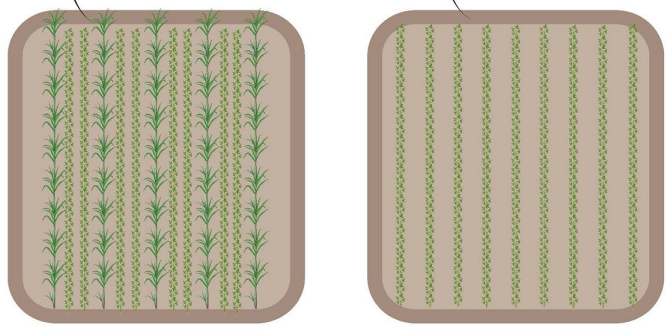

B

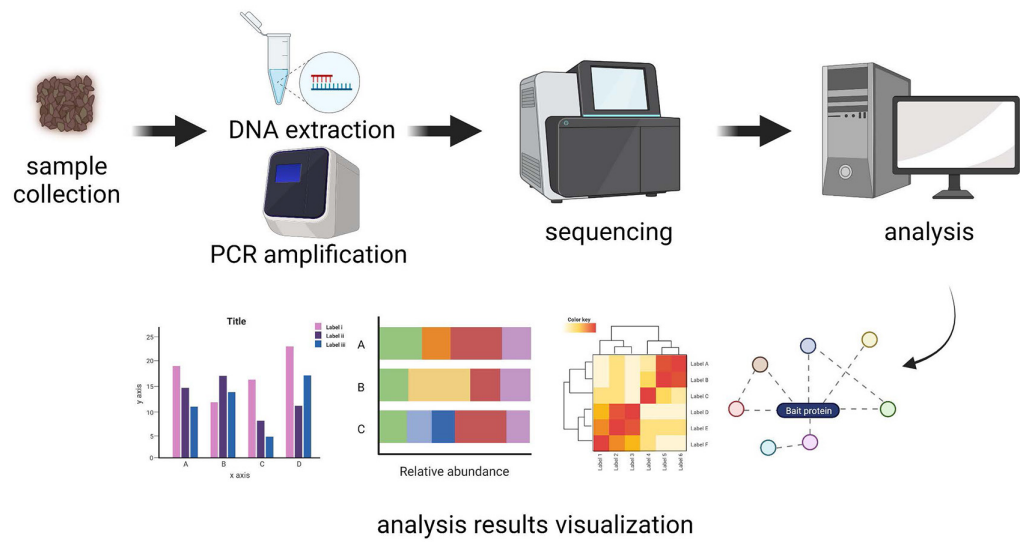

FIGURE 1 | (A) Self-interpretation diagram of experimental design. (B) Simple explanation of metagenomic analysis process.

(Biometra, Goettingen, Germany). Illumina TruSeq DNA sample preparation kit (Illumina, San Diego, CA, United States) was used for the construction of DNA libraries. Illumina HiSeq 2,500 platform (Illumina, San Diego, CA, United States) was used to perform high-throughput sequencing of amplified 16S rRNA sequences, and $250 \mathrm{bp}$ of paired-end reads were obtained. There is a simple flow chart to understand our metagenomic analysis process (Figure 1B).

\section{Bioinformatics}

Mothur (version 1.35.1) was used to assign the original tag sequence to unique barcodes and primers to obtain clean reads (Schloss et al., 2009). Further, to acquire tags, FLASH (version 1.2.7) ${ }^{1}$ was used to pair clean reads (Liang et al., 2019) and

${ }^{1}$ http://ccb.jhu.edu/software/FLASH/
USEARCH (Version 8.1.1861) ${ }^{2}$ was used to analyze the sequence. The 16S rRNA gene sequence was clipped to a fixed length of $360 \mathrm{bp}$, sorted by abundance, de-replicated, and clustered using UPARSE (version 7.1) ) $^{3}$ determine operational taxonomic units (OTUs) with a $97 \%$ similarity (Chen et al., 2020). UCHIME $(\mathrm{v} 4.2 .4,025)^{4}$ was used to remove chimeric sequences against the GOLD database (Sekoai et al., 2020). SILVA database was used for taxonomies classification (Bai et al., 2020).

\section{Diversity Analysis}

Alpha diversity was investigated using QIIME (version 1.9.1) (Caporaso et al., 2010). R software (version 2.15.3) was used to display the diversity of samples (R Core Team, 2011). Shannon

\footnotetext{
${ }^{2}$ http://www.drive5.com/usearch/

${ }^{3} \mathrm{http}: / /$ drive5.com/uparse/

${ }^{4} \mathrm{http}: / /$ drive5.com/uchime
} 
index and Chaol index were used to identify community diversity. The data involved are the data fitting of 6 replicate samples to ensure the reliability of the results. Beta diversity was analyzed using principal coordinate analysis ( $\mathrm{PCoA}$ ) based on the Bray-Curtis distance to show the differences between the bacterial community species composition (Tai et al., 2015). The filtered OTU sequence count was normalized using the "trimmed means of M" (TMM), and the normalized results were counted as "count per million” (CPM) (Lee et al., 2016; Fernández-González et al., 2020). We used permutational multivariate analysis of variance (PERMNOVA) to investigate the effects of sample types and intercropping patterns on community differences. Analysis of similarity (ANOSIM) was used to determine the significance of differences in the bacterial community structure under different planting patterns. The correlation between the host root biomass and the rhizosphere compositional similarity was determined using the Mantel test implemented in the Vegan package in $\mathrm{R}$ (Hernández et al., 2020).

\section{Bipartite and Co-occurrence Networks}

Indicator analysis for significant planting patterns $(p<0.05)$ was conducted using bipartite network visualization. For all networks, we used the TMM normalization, and Spearman's correlation analysis between the OTUs. In addition, we used Spearman's correlation analysis to assess the association between environmental factors and rhizosphere bacteria to determine the topological network attributes. For this, we included TMMstandardized CPM bacterial count in the OTU table of soil and root communities and used Spearman's rank correlation analysis to evaluate the correlation between the bacterial OTUs. The network properties were summarized and analyzed, network modules were identified, and the community structure of each plant unit network was analyzed (Hartman et al., 2018). OTUs with network node degree values in the top $1 \%$ of nodes in each planting mode were identified as the key meta-network OTUs. We prioritized this simple definition over the other complex definition because both definitions essentially reveal the same keystone OTUs. Further, the correlation between the modules and soil environmental factors was investigated through the Mantel test (Tai et al., 2020).

\section{RESULTS}

\section{Comparison of Biomass and Soil Nutrients Between Two Intercropping Models}

Compared with those of monocropped soybean (Table 1), both WT and GM sugarcane intercropping patterns increased the aboveground and root biomass of soybeans significantly; the GM sugarcane-soybean intercropping pattern produced the highest soybean aboveground and root biomass. Compared with WT, GM sugarcane had a higher aboveground biomass and root biomass when intercropped with soybean. In terms of soil nutrients, the SOC, TN, and AP contents were higher in InterSoy than in Mono-Soy. The SOC and TN contents were higher,
TABLE 1 | Soil characteristics of different patterns.

\begin{tabular}{|c|c|c|c|c|c|}
\hline Sample & $\begin{array}{l}\text { Root biomass } \\
\text { (g) }\end{array}$ & $\begin{array}{l}\text { Above ground } \\
\text { biomass(g) }\end{array}$ & $\begin{array}{c}\text { soc } \\
\left(g \cdot \mathrm{kg}^{-1}\right)\end{array}$ & $\begin{array}{c}\mathrm{TN} \\
\left(\mathrm{g} \cdot \mathrm{kg}^{-1}\right)\end{array}$ & $\begin{array}{c}\text { AP } \\
\left(\mathrm{g} \cdot \mathrm{kg}^{-1}\right)\end{array}$ \\
\hline Mono-soy & $7.15 c$ & $29.10 d$ & $5.32 d$ & $0.537 a$ & $3.51 \mathrm{c}$ \\
\hline WT Mono-sug & $24.24 b$ & $118.44 b$ & $5.23 d$ & $0.369 a$ & 4.67ab \\
\hline WT Inter-sug & $31.20 a b$ & $147.60 \mathrm{ab}$ & $7.18 \mathrm{bc}$ & $0.400 a$ & $5.83 a$ \\
\hline WT Inter-soy & $8.50 c$ & $34.95 d$ & $5.59 \mathrm{~cd}$ & $0.393 a$ & $5.63 a$ \\
\hline GM Mono-sug & $25.04 b$ & $82.56 \mathrm{bc}$ & $5.73 \mathrm{~cd}$ & $0.505 a$ & $2.39 d$ \\
\hline GM Inter-sug & $35.40 a$ & $176.16 a$ & $9.84 a$ & $0.707 a$ & $4.03 \mathrm{bc}$ \\
\hline GM Inter-soy & $10.85 c$ & $44.35 \mathrm{~cd}$ & $7.67 \mathrm{~b}$ & $0.622 a$ & $3.85 b c$ \\
\hline
\end{tabular}

Different letters indicate significant differences (ANOVA, $P<0.05$ ).

but the AP content was lower in GM intercropping than in WT intercropping systems.

\section{Rhizosphere Community Diversity Under Genetically Modified and Wild-Type Sugarcane Intercropping With Soybean}

Alpha diversity analysis revealed that intercropping improved the rhizosphere microbial diversity and abundance of soybean compared with monocropping, and the differences in the Chaol index between WT Inter-Soy and WT Inter-Sug were not significant. Significant difference in the Shannon index was registered only between GM sugarcane-soybean intercropping and soybean monocropping (Figure 2A). The Pearson's correlation analysis of the alpha diversity and nutrients showed that in the WT sugarcane-soybean intercropping pattern, the Shannon index was negatively correlated with TN and positively correlated with AP, whereas the Shannon and Chaol indexes were significantly correlated with each other, but not with the soil environmental factors (Figure 2B).

Beta diversity analysis for the two intercropping patterns was presented by PCoA of unweighted and weighted UniFrac distance matrices (Figure 3A). PCoA of the unweighted and weighted UniFrac distances revealed a significant difference between the GM sugarcane-soybean and the WT sugarcanesoybean intercropping patterns. The unweighted-based PCoA showed a larger significant difference in the soybean rhizosphere between GM sugarcane-soybean intercropping and monocropped soybean; after weighting, no significant difference in the soybean rhizosphere bacteria was observed between the two intercropping patterns. According to the Mantel test under the unweighted conditions, the two intercropping patterns showed significant differences in $\mathrm{TN}$, SOC, root biomass, and aboveground biomass, with GM being more strongly correlated with $\mathrm{TN}$, SOC, and biomass (Figure 3B). After weighting, the two intercropping patterns showed significant differences in $\mathrm{TN}$ and SOC, and the GM sugarcane was more significantly correlated with TN and SOC.

Compared with the monocropped soybean plots, there was a higher relative abundance of Actinobacteria and a lower relative abundance of Betaproteobacteria in the GM intercropping pattern. The comparison of soybean intercropping patterns revealed a higher relative abundance of Actinobacteria 

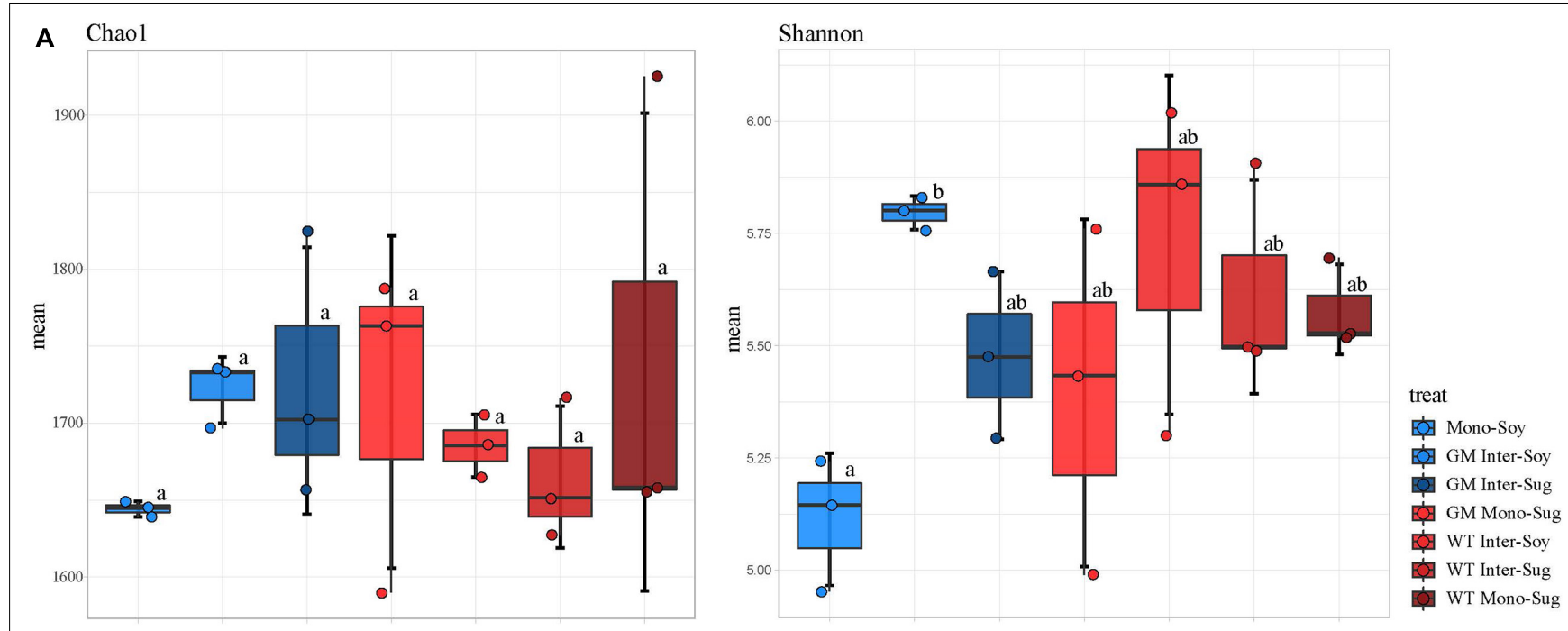

B
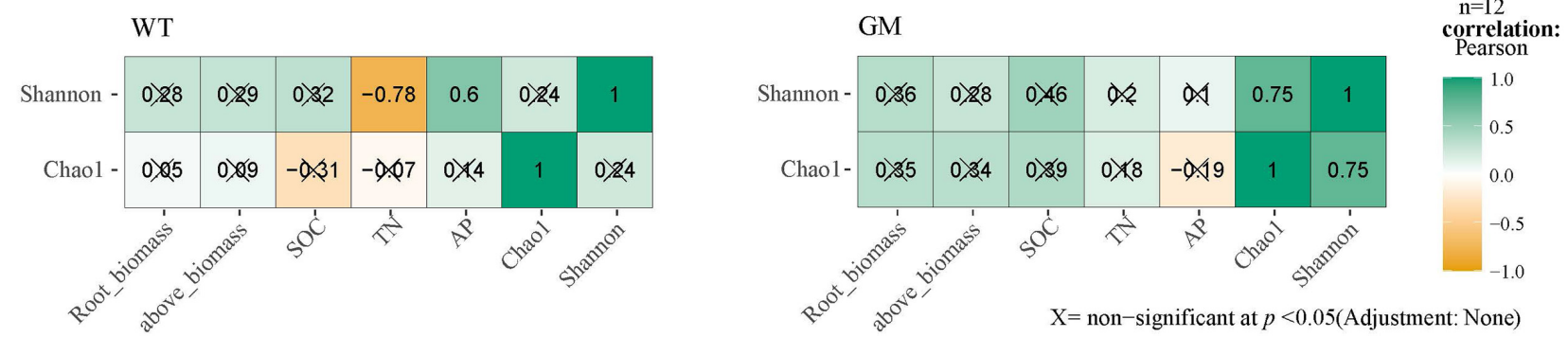

FIGURE 2 | (A) The results of Chao 1 index and Shannon index showed the $\alpha$-diversity of bacteria. F, Fisher's F-ratio. $p, p$-value. The letters next to the bar chart indicate the significant differences between the processed data. (B) Pearson analysis of the correlation between bacterial $\alpha$-diversity and environmental factors.

in the GM sugarcane-soybean intercropping pattern, and a higher relative abundance of Betaproteobacteria in soybean intercropping with WT sugarcane (Figure 4A). In addition, compared with WT Mono-Sug, GM sugarcane intercropping increased the relative abundance of Actinobacteria, but reduced the relative abundance of Bacteroidetes. GM Inter-Soy had a higher relative abundance of Actinobacteria, but a lower relative abundance of Betaproteobacteria compared with Mono-Soy. The comparison of the two intercropping patterns revealed a higher relative abundance of Actinobacteria in GM InterSoy, and a higher relative abundance of Betaproteobacteria in WT Inter-Soy (Figure 4A). In addition, GM MonoSug also had a higher relative abundance of Actinobacteria, but a lower relative abundance of Bacteroidetes compared with that of WT Mono-Sug. The correlation between environmental factors and each component (Mono-Soy, Inter-Soy, Inter-Sug, and Mono-Sug) in the two intercropping patterns was further explored through dbRDA analysis. The first two axes of dbRDA accounted for 52.2 and $33.8 \%$ of the total variation, respectively, for the two intercropping patterns (Figure 4B). AP was highly correlated with spindle 1, while SOC was highly correlated with spindle 2 . Compared with GM Inter-Soy, Mono-Soy showed a large difference in distance, and was mainly influenced by TN and
SOC. The distributions of WT and GM components were significantly different.

\section{Genetically Modified and Wild-Type Sugarcane Intercropping Patterns Produced Different Rhizosphere Co-occurrence Network Interactions}

A bipartite network was used to analyze the cluster relation of the responsive OTUs in the two intercropping patterns. More responsive OTUs were clustered, and the components were more closely related to each other in the GM intercropping pattern than in the WT intercropping pattern. The GM sugarcanesoybean intercropping pattern could cluster more Actinobacteria (Figure 5). By analyzing OTUs of the corresponding treatments in the two intercropping modes at the genus level, it was found that there were more OTUs responding to GM sugarcane and soybean intercropping pattern, and the corresponding genera were also different. For example, the top three genera responding to GM Inter-Sug. Taibaiella (10), Rhodanobacter (9) and Sphingomonas (7); Gemmatimonas (4), Nocardioides (4), and Lysobacter (3) responded to WT intercropping pattern. In addition, Sphingomonas had higher response numbers in both GM Inter-Sug and GM Mono-Sug. Gemmatimonas and 


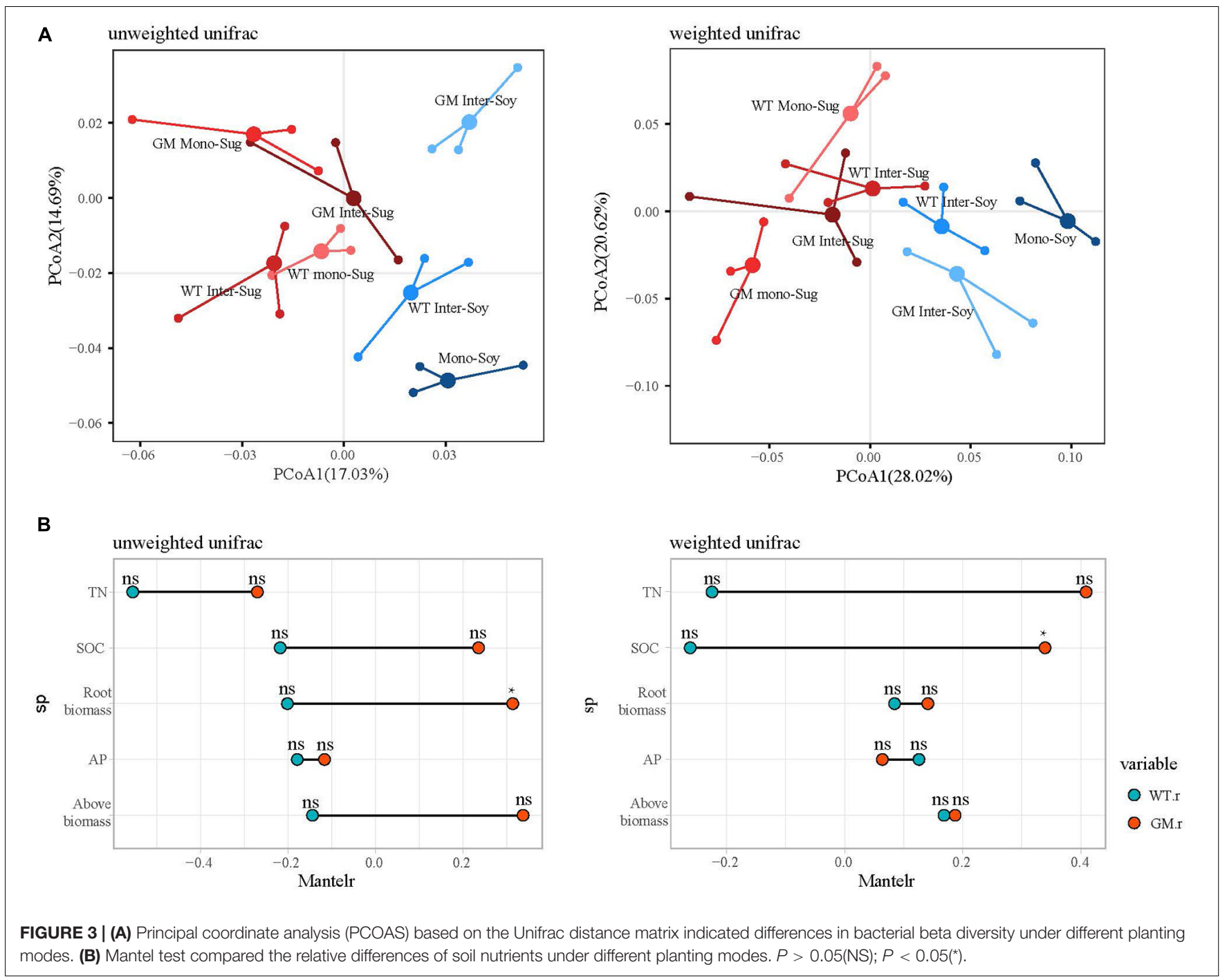

Nocardioides had higher response numbers in both WT InterSug and WT Mono-Sug, and Gemmatimonas also had more OTUs responses in WT Inter-Soy (Supplementary Tables 1, 2 and Supplementary Figure 2). The co-occurrence network analysis revealed a significant correlation between the OTUs in the rhizosphere bacterial communities under the two intercropping patterns (Figure 6A). In the WT sugarcanesoybean intercropping pattern, module2 (M2) contained OTUs corresponding to Mono-Soy, while module1 (M1) mainly contained OTUs analogous to Inter-Sug and Mono-Sug (Figure 6B). In the GM sugarcane-soybean intercropping pattern, module3 (M3) contained OTUs that corresponded to Inter-Soy, while module2 (M2) and module5 (M5) mainly contained OTUs that corresponded to Inter-Sug and MonoSug. Compared with the WT sugarcane-soybean intercropping pattern, more responsive OTUs were detected in the GM intercropping pattern network, and many OTUs corresponded to both soybean and GM sugarcane (Figure 6A). The analysis of responding OTUs in genus level of each module in network analysis showed that Streptomyces, Nocardioides and
Sphingomonas were the most responding bacteria in M2 and M5 modules of GM sugarcane soybean intercropping pattern (Supplementary Tables 3, 4). This also verified the result of the cluster analysis of OTUs in the binary network for each treatment in the two intercropping patterns (Supplementary Tables 1, 2). Classifying the OTUs in each module at the phylum level revealed a large difference between the two intercropping patterns-WT had a higher relative abundance of Bacteroidetes, while GM had a higher relative abundance of Actinobacteria (Figure 6C). In the node degree analysis, a higher node degree was observed for OTUs in response to soybean in the WT intercropping and for OTUs in response to sugarcane in the GM intercropping pattern (Supplementary Figure 1). In addition, the results of the Mantel tests revealed that M2 was generally significantly correlated with the biomass and environmental factors, except $\mathrm{TN}$, and significantly correlated with SOC in the GM intercropping pattern. The WT intercropping pattern showed no significant correlation between each module and the environmental factors (Figure 7). 

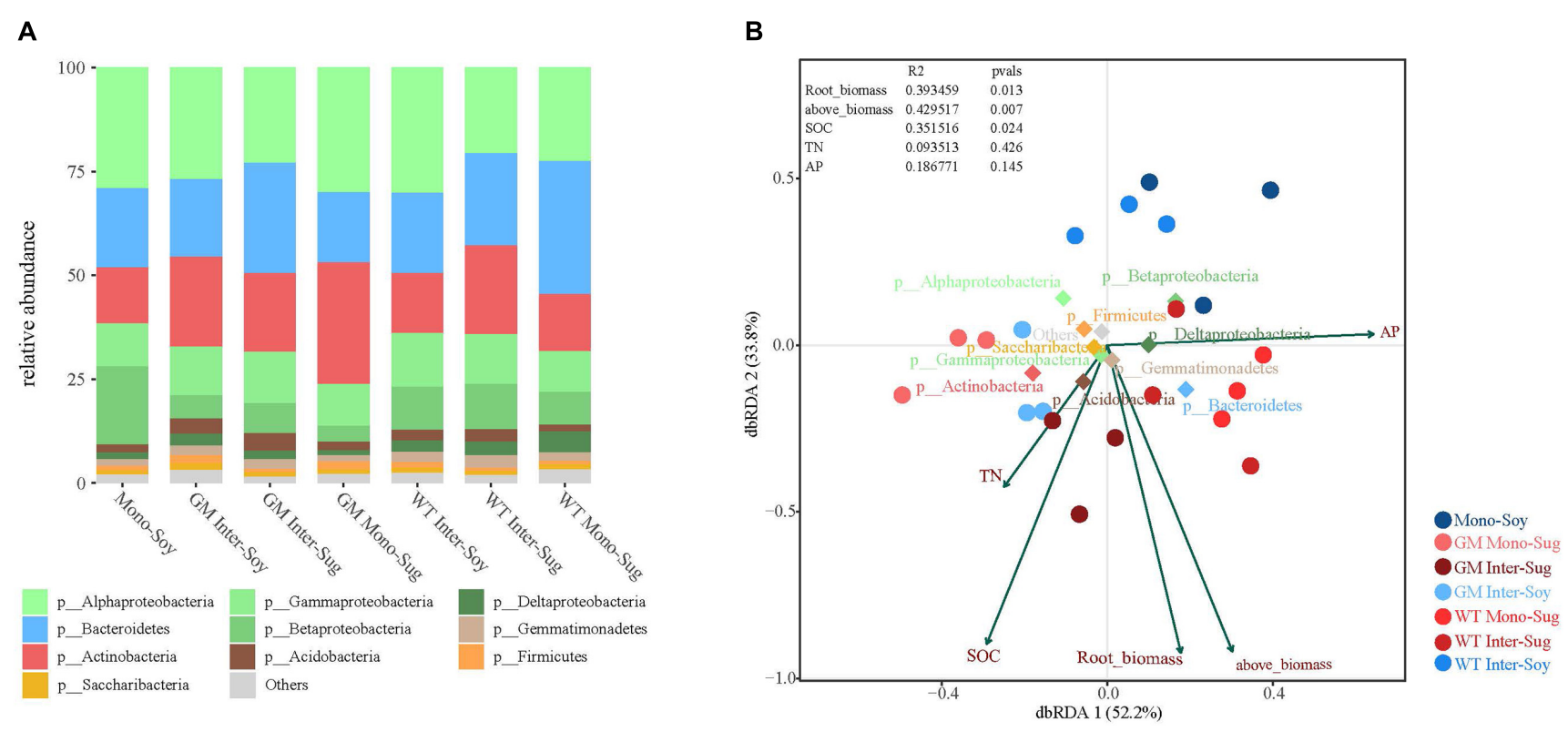

FIGURE 4 | (A) Relative abundance of different phyla in each pattern. (B) Distance-based Redundancy analysis of different patterns (dot), abundant classes (rhombus), and environmental factors (arrows) indicates the dominant communities and influential environmental factors.

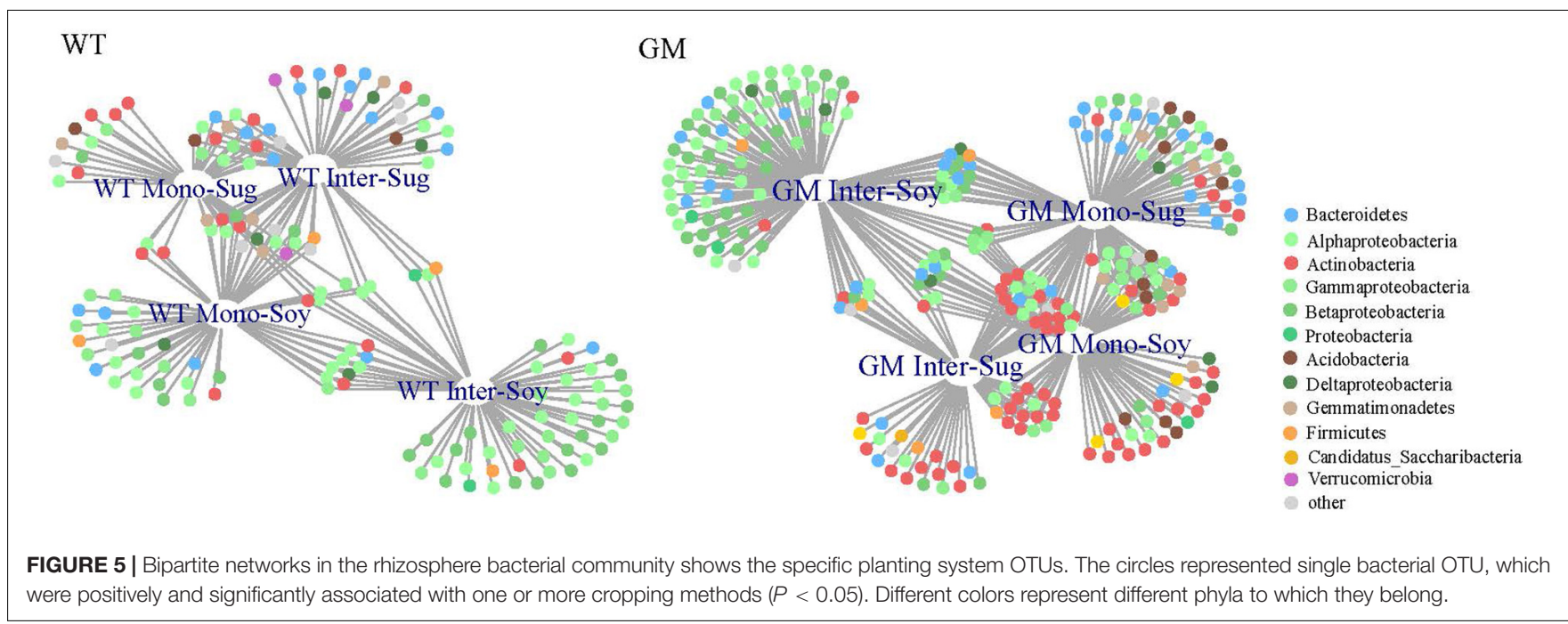

\section{DISCUSSION}

\section{Soybean Rhizosphere Bacterial Communities Differ Between Genetically Modified and Wild-Type Intercropping Patterns}

The alpha diversity results indicated that sugarcane-soybean intercropping increased the diversity of the bacterial community in soybean roots and intercropping with GM sugarcane significantly improved the bacterial diversity of the soybean rhizosphere (Figure 2A). SOC and TN under the GM sugarcanesoybean intercropping pattern significantly improved compared with those under the WT sugarcane-soybean intercropping pattern (Table 1). Based on these findings, we speculated that the root system of GM sugarcane releases more exudates, such as sugars and organic acids, which provide nutrients and vitamins required for bacterial growth, alter soil properties, and thereby promote the development of different rhizosphere microbial communities (Da Costa et al., 2018; Sasse et al., 2018; Pereira et al., 2019). Intercropping can also change the SOC content in the rhizosphere of crops and affect the community structure of rhizosphere bacteria (Zhou Q. et al., 2019). Pearson's correlation analysis revealed that the WT and GM sugarcane bacterial communities had different relationships with the environmental factors (Figure 2B), 

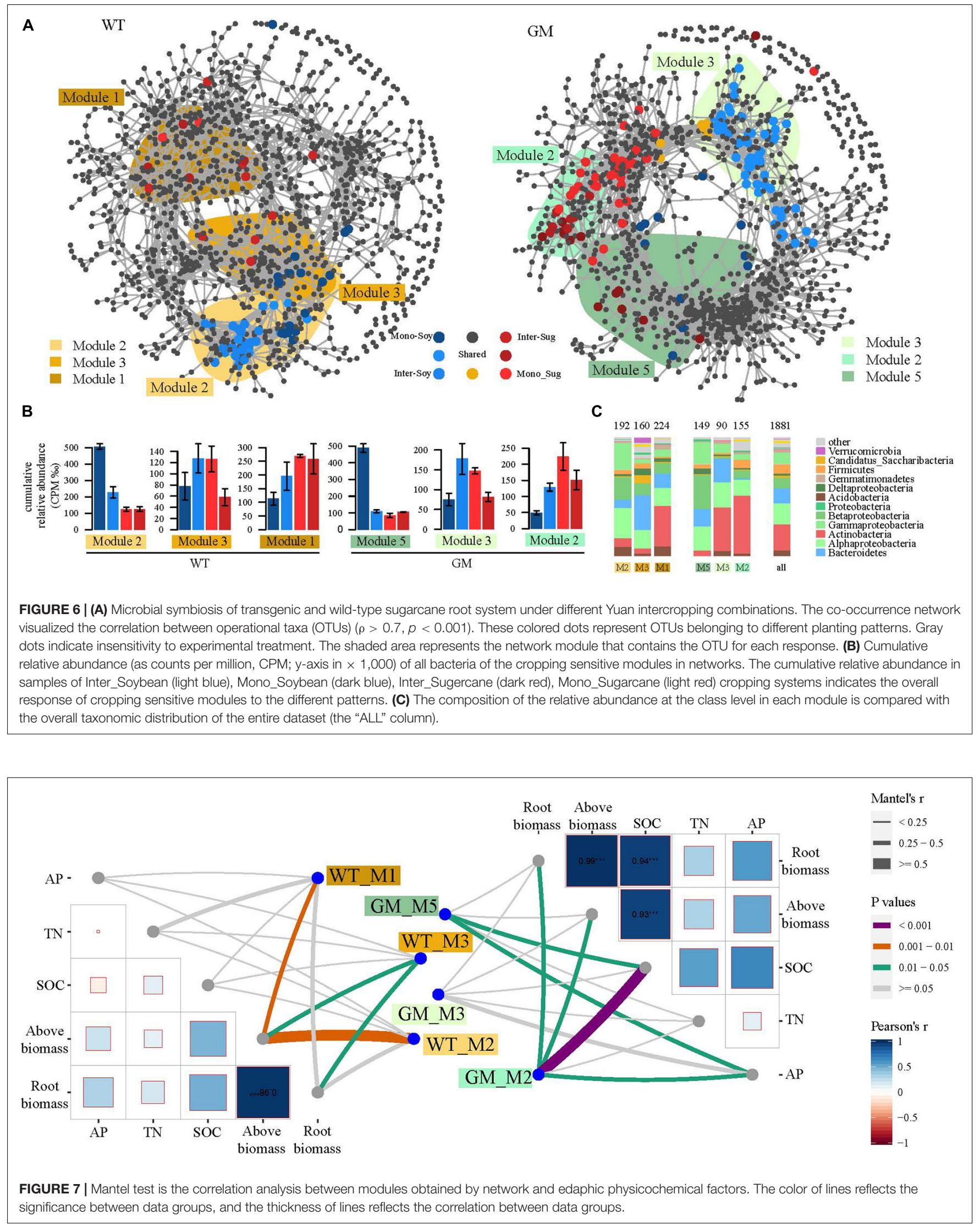
which further demonstrated that the two sugarcane varieties may shape different rhizosphere bacterial structures due to their influences on soil environmental factors (Zhang et al., 2016). Direct contact between the roots of two intercropped plants leads to interactions between their root exudates, which in turn affects the bacterial community structure (Gao et al., 2019; Yu et al., 2019). Therefore, we speculated that root exudation may play a positive role in maintaining or modifying the community structure of rhizosphere soil microbes, the enrichment of which may considerably impact plant growth (Huangfu et al., 2019). The beta diversity analysis showed that the composition of the rhizosphere bacterial community differed between the GM sugarcane-soybean and WT sugarcane-soybean intercropping patterns, and that the community structure of the soybean rhizosphere bacteria was modified by the interaction between GM sugarcane and soybean roots (Figure 3A). Thus, the expression of drought resistant genes could enrich the bacterial community and improve the rhizosphere environment compared with those in the WT intercropping pattern (Sayer et al., 2017). The Mantel test indicated that GM sugarcane was more closely related to the environmental factors than was WT, especially to $\mathrm{TN}$ and SOC (Figure 3). This indicated that the changes in the rhizosphere soil environment can affect the diversity of the bacterial community (Zhao et al., 2020a). Previous studies have shown that the overexpression of Ea-DREB2 in GM sugarcane increases the photosynthetic rate and chlorophyll content of sugarcane (Augustine et al., 2015). Plants may release up to $20 \%$ of their photosynthetic products into the rhizosphere soil, which provides the nutritional basis for establishing the plant-microbes interactions (Haichar et al., 2008). Rhizosphere bacteria in the soil can release growthpromoting compounds that promote the establishment of compact soil structure, contribute to the dissolution of organic compounds and release of minerals, and interact with plant roots to support plant growth (Igiehon and Babalola, 2018). In addition, the rhizosphere microbiome can have a considerable effect on plant health by enhancing the abiotic stress tolerance of plants (Zancarini et al., 2013). Therefore, we conclude that the drought-tolerant GM sugarcane cultivar secreted and accumulated large amounts of rhizosphere and soil nutrients, which contributed to the evidently different rhizosphere bacterial community of soybean intercropped with the droughttolerant sugarcane compared with that of soybean intercropped with WT sugarcane.

\section{Intercropping of Genetically Modified Sugarcane and Soybean Alters the Rhizosphere Soil Environment}

Compared with WT sugarcane, cultivation of GM sugarcane increased the abundance of Actinobacteria when monocropped and increased the relative abundance of Actinobacteria in the soybean rhizosphere when intercropped (Figure 4A). Previous studies have demonstrated that in fields intercropped with GM sugarcane and soybean, the GM sugarcane released larger amounts of nutrients into the soybean rhizosphere, which led to a close interaction between the roots of soybean and those of GM sugarcane, an increase in the number of rhizosphere bacterial species, and the expansion of the GM sugarcane rhizosphere (Gong et al., 2019; Zhou Q. et al., 2019). The introduction of drought-resistance genes has been shown to enhance the secretion of root exudates, which further shapes and influences the rhizosphere microbial community of intercropped soybean (Chun-miao et al., 2015). Moreover, a higher diversity of bacterial species around or in the roots plays an important role in the recycling of soil nutrients, and thus, improves soil fertility (Lisuma et al., 2020). Compared with WT sugarcane intercropping, the abundance of Actinobacteria was higher in Inter-Sug (Figure 4A), thus, contributing to higher nitrogen fixation, ferrite synthesis, phytohormone synthesis, and solubilization of minerals, which enhanced their availability to plants (Barka et al., 2016). Peng et al. (2014) reported that sugarcane and soybean intercropping had a significant effect on the diversity of sugarcane rhizosphere nitrogen-fixing bacteria. GM sugarcane improved the rhizosphere microenvironment of soybean by secreting root exudates, altered the specific flora (such as Actinobacteria and Betaproteobacteria), and promoted the growth of soybean (Sasse et al., 2018; Xu et al., 2018). Actinobacteria dominate the microbiota in plant roots owing to the close relationship between roots and soil bacteria (Liu et al., 2019). They have the potential to promote plant growth and are known to play important roles in nitrogen mineralization and breakdown of organic materials, such as chitin and cellulose (Hamdali et al., 2008; Li et al., 2010). The difference in relative abundance of Betaproteobacteria is mainly reflected in the mono-cropping of GM and WT sugarcane. That is, the two sugarcane cultivars enrich different bacteria in the soil, and Betaproteobacteria also has a positive effect on plant growth, Burkholderia secrete organic acids or acid phosphatases to convert insoluble phosphorus in soil into soluble phosphorus that can be directly absorbed and utilized by plants, thus promoting the utilization of soil phosphorus by plants (Peix et al., 2001; CaballeroMellado et al., 2007). Similarly, Flavobacterium is a genus in Bacteroidetes with higher relative abundance in WT intercropping system, which has the ability of promoting plant growth, biological control and inducing plant systemic resistance, but its abundance in WT intercropping system is still not high (Jaiswal et al., 2017). The dbRDA analysis between the two intercropping patterns and environmental factors revealed significant differences in the correlation between these factors. These differences were mainly affected by the SOC and AP contents (Figure 4B). Previous studies have suggested that plants drive and shape the structure of rhizosphere bacterial communities by secreting specific compounds in root exudates, and that the species enriched in these communities often play a positive role in plant growth (Li et al., 2019; Cao et al., 2020). In addition, the activation of these rhizosphere nutrients is triggered by the activity of rhizosphere microbes (Zheng et al., 2018). The bipartite network revealed higher abundance in clustered OTUs in GM sugarcane-soybean than in WT sugarcane intercropping systems, 
which indicates that the rhizosphere bacterial community of GM sugarcane is more closely related to soybean, and that GM sugarcane promotes the soybean biomass (Figure 5). A variety of plant growth-promoting rhizobacteria (PGPR) are enriched, thus, changing the rhizosphere environment and activating more nutrients in the soil (Wang et al., 2017; Gouda et al., 2018).

\section{Intercropping Between Genetically Modified Sugarcane and Soybean Promotes the Growth of These Crops}

Differences between GM sugarcane-soybean intercropping and WT sugarcane-soybean intercropping in rhizosphere bacterial community networks revealed that the expression of $D R E B$ gene enhanced the intraspecific competition between sugarcane cultivars, and made OTUs response of rhizosphere community stronger (Figures 6A,B). This may be related to the fact that the root interaction between soybean and GM sugarcane is stronger than that between soybean and WT sugarcane (Zhao et al., 2020b). This was also confirmed by the node degree analysis (Supplementary Figure 1). Owing to the interaction between sugarcane and soybean roots and their exudates, the bacteria enriched in the transgenic sugarcane intercropping pattern were more closely related than those enriched in the wild-type sugarcane intercropping pattern (Fan et al., 2017). This was further confirmed by the network analysis of GM and WT sugarcane intercropping patterns, which showed a closer connection between the Inter-Sug and Inter-Soy in GM intercropping pattern (Figure 5). Therefore, the bacteria showed a higher population correlation, in other words, the rhizosphere between GM sugarcane and soybean root had higher contact levels (Lareen et al., 2016). In addition, genus such as Taibaiella and Rhodanobacter that respond to GM sugarcane soybean intercropping have been identified as PGPR and play an important role in hydrocarbon degradation (Zhang et al., 2013; Gutierrez, 2019; Diallo et al., 2021). The GM sugarcanesoybean intercropping pattern significantly increased the biomass these of the two crops compared with that of WT intercropping pattern (Table 1); thus, intercropping of GM sugarcane and soybean will promote the growth of both species. We speculated that the existence of a close interaction between the GM sugarcane and soybean root systems increased the similarity between the soybean and GM sugarcane rhizosphere bacterial species, provided a higher abundance of soil nutrients and promoted soybean root growth. The GM sugarcane rhizosphere harbored a higher abundance of Actinobacteria (Figure 6C). In the soil, Actinobacteria play important roles in the decomposition of refractory biomaterials and the formation of humus (Anandan et al., 2016). Actinobacteria have a variety of characteristics that promote plant growth directly via the production of plant growth hormones (indole-3-acetic acid, cytokinin, gibberellin, and abscisic acid), biological nitrogen fixation, and solubilization (Yadav et al., 2018; Sekaran et al., 2019). The diversity of the GM sugarcane rhizosphere community was significantly correlated with root biomass, and the structural composition of the rhizosphere bacterial community of soybean intercropped with sugarcane was closely correlated with soybean biomass (Figure 7). Many PGPR affect the plant hormone balance and stress responses by altering plant hormone levels (Tsukanova et al., 2017). The enrichment of a variety of PGPR can both alter the microbial community in the soil around soybean root systems and colonize the root systems themselves (Trabelsi and Mhamdi, 2013). The PGPR can synthesize important growth hormones (e.g., auxins, cytokinins, and gibberellins) that directly promote root growth (Lugtenberg et al., 2013), produce iron carriers, or promote nitrogen fixation and phosphate solubilization to improve soil fertility, and indirectly promote root growth (Bhardwaj et al., 2014). Our findings indicated that intercropping between GM sugarcane and soybean can beneficially modify the bacterial community in the soybean rhizosphere, enhance the abundance and diversity of PGPR, improve soil fertility, regulate plant hormone levels in soybean roots, and promote soybean root growth.

\section{CONCLUSION}

In this study, we investigated the effects of intercropping soybean with GM and WT sugarcane on the rhizosphere bacterial community and biomass of the crops. Intercropping with GM and WT sugarcane resulted in the formation of different rhizosphere bacterial communities, with the former enhancing the number of representative species of Actinobacteria around the roots of soybean. This result is attributed to the production of larger amounts of root exudates by GM sugarcane roots that have a stimulatory effect on rhizosphere bacterial community development. Furthermore, the GM sugarcane intercropping pattern showed a higher microbial population correlation, and had a stronger positive effect on crop growth than the WT sugarcane intercropping pattern. We also found that the roots of soybean interacted closely with those of GM sugarcane, thereby increasing the similarity between the rhizosphere bacterial species compositions of these two crops. Intercropping with GM sugarcane was shown to improve the microbial communities of the rhizosphere, thereby promoting crops root growth. Therefore, the intercropping pattern of GM sugarcane and soybean is of great value for increasing crop yield and improving the microbial environment of rhizosphere soil. 


\section{DATA AVAILABILITY STATEMENT}

The datasets presented in this study can be found in online repositories. The names of the repository/repositories and accession number(s) can be found below: https://www.ncbi.nlm. nih.gov/, PRJNA597165.

\section{AUTHOR CONTRIBUTIONS}

BW: visualization and data curation. JZ: investigation, validation, and formal analysis. RW: writing-review and editing and software. NX and TC: revision. YL: writing-original draft preparation and investigation. ZW: conceptualization and methodology. All authors contributed to the article and approved the submitted version.

\section{REFERENCES}

Ali, F., Bano, A., and Fazal, A. (2017). Recent methods of drought stress tolerance in plants. Plant Growth Regul. 82, 363-375.

Anandan, R., Dharumadurai, D., and Manogaran, G. P. (2016). “An introduction to actinobacteria," in Actinobacteria-Basics and Biotechnological Applications, eds D. Dhanasekaran and Y. Jiang (London: Intechopen).

Augustine, S. M., Ashwin Narayan, J., Syamaladevi, D. P., Appunu, C., Chakravarthi, M., Ravichandran, V., et al. (2015). Overexpression of EaDREB2 and pyramiding of EaDREB2 with the pea DNA helicase gene (PDH45) enhance drought and salinity tolerance in sugarcane (Saccharum spp. hybrid). Plant Cell Rep. 34, 247-263. doi: 10.1007/s00299-014-1704-6

Bai, Y., Chang, Y., Hussain, M., Lu, B., and Pei, D. J. M. (2020). Soil Chemical and Microbiological Properties Are Changed by Long-term Chemical Fertilizers That Limit Ecosystem Functioning. Microorganisms 8:694.

Barka, E. A., Vatsa, P., Sanchez, L., Gaveau-Vaillant, N., Jacquard, C., Klenk, H.-P., et al. (2016). Taxonomy, physiology, and natural products of Actinobacteria. Microbiol. Mol. Biol. Rev. 80, 1-43. doi: 10.1128/mmbr.000 19-15

Beck, D., Dennis, C., and Foster, J. A. (2015). Seed: a user-friendly tool for exploring and visualizing microbial community data. Bioinformatics 31, 602-603. doi: 10.1093/bioinformatics/btu693

Bhardwaj, D., Ansari, M. W., Sahoo, R. K., and Tuteja, N. (2014). Biofertilizers function as key player in sustainable agriculture by improving soil fertility, plant tolerance and crop productivity. Microb. Cell Fact. 13, 1-10. doi: 10.1186/14752859-13-66

Bremner, J., and Tabatabai, M. (1972). Use of an ammonia electrode for determination of ammonium in Kjeldahl analysis of soils. Commun. Soil Sci. Plant Anal. 3, 159-165.

Budak, H., Hussain, B., Khan, Z., Ozturk, N. Z., and Ullah, N. (2015). From genetics to functional genomics: improvement in drought signaling and tolerance in wheat. Front. Plant Sci. 6:1012. doi: 10.3389/fpls.2015.01012

Caballero-Mellado, J., Onofre-Lemus, J., Estrada-De, L. S. P., and MartinezAguilar, L. (2007). The Tomato Rhizosphere, an Environment Rich in NitrogenFixing Burkholderia Species with Capabilities of Interest for Agriculture and Bioremediation. Appl. Environ. Microbiol. 73, 5308-5319. doi: 10.1128/AEM. 00324-07

Cao, X., Luo, J., Wang, X., Chen, Z., Liu, G., Khan, M. B., et al. (2020). Responses of soil bacterial community and Cd phytoextraction to a Sedum alfredii-oilseed rape (Brassica napus L. and Brassica juncea L.) intercropping system. Sci. Total Environ. 723:138152. doi: 10.1016/j.scitotenv.2020.138152

Caporaso, J. G., Kuczynski, J., Stombaugh, J., Bittinger, K., Bushman, F. D., Costello, E. K., et al. (2010). QIIME allows analysis of high-throughput community sequencing data. Nat. Methods 7, 335-336.

Chen, Y., Sun, R., Sun, T., Liang, Y., Jiang, Y., and Sun, B. (2018). Organic amendments shift the phosphorus-correlated microbial co-occurrence pattern

\section{FUNDING}

This work was supported by Guangxi Natural Science Foundation (Project No. 003107157015).

\section{ACKNOWLEDGMENTS}

We thank the reviewers and the editors for their constructive comments on this manuscript.

\section{SUPPLEMENTARY MATERIAL}

The Supplementary Material for this article can be found online at: https://www.frontiersin.org/articles/10.3389/fmicb. 2021.742341/full\#supplementary-material

in the peanut rhizosphere network during long-term fertilization regimes. Appl. Soil Ecol. 124, 229-239. doi: 10.1016/j.apsoil.2017.11.023

Chen, Z., Zhijie, C., Yuting, Z., Shilin, X., Qichun, Z., Jinying, O., et al. (2020). Antibiotic-Driven Gut Microbiome Disorder Alters the Effects of Sinomenine on Morphine-Dependent Zebrafish. Front. Microbiol. 11:946. doi: 10.3389/ fmicb.2020.00946

Chun-miao, Z., Lei, D., Yu, J., and Juan-Juan, Q. (2015). Effects of Transgenic DREB Toybean Dongnong50 on diversity of soil nitrogen-fixing bacteria. J. Northeast Agric. Univ. 22, 1-11.

Cui, J.-Q., Sun, H.-B., Sun, M.-B., Liang, R.-T., Jie, W.-G., and Cai, B.-Y. (2018). Effects of Funneliformis mosseae on root metabolites and Rhizosphere soil properties to continuously-cropped soybean in the potted-experiments. Int. J. Mol. Sci. 19:2160. doi: 10.3390/ijms19082160

Da Costa, D. P., Dias, A. C., Cotta, S. R., Vilela, D., De Andrade, P. A., Pellizari, V. H., et al. (2018). Changes of bacterial communities in the rhizosphere of sugarcane under elevated concentration of atmospheric $\mathrm{CO}_{2}$. GCB Bioenergy 10, 137-145. doi: 10.1111/gcbb. 12476

DeBruyn, J. M., Bevard, D. A., Essington, M. E., Mcknight, J. Y., Schaeffer, S. M., Baxter, H. L., et al. (2017). Field-grown transgenic switchgrass (Panicum virgatum L.) with altered lignin does not affect soil chemistry, microbiology, and carbon storage potential. GCB Bioenergy 9, 1100-1109. doi: 10.1111/gcbb. 12407

Diallo, M., Vural, C., Cay, H., and Ozdemir, G. (2021). Enhanced biodegradation of crude oil in soil by a developed bacterial consortium and indigenous plant growth promoting bacteria. J. Appl. Microbiol. 130, 1192-1207. doi: 10.1111/ jam. 14848

Du, J.-B., Han, T.-F., Gai, J.-Y., Yong, T.-W., Xin, S., Wang, X.-C., et al. (2018). Maize-soybean strip intercropping: achieved a balance between high productivity and sustainability. J. Integr. Agric. 17, 747-754.

Edgar, R. C. (2010). Search and clustering orders of magnitude faster than BLAST. Bioinformatics 26, 2460-2461. doi: 10.1093/bioinformatics/btq461

El-Metwally, S., Ouda, O. M., and Helmy, M. (2014). Next Generation Sequencing Technologies and Challenges in Sequence Assembly. New York, NY: Springer, 37-44.

Fan, K., Cardona, C., Li, Y., Shi, Y., Xiang, X., Shen, C., et al. (2017). Rhizosphere-associated bacterial network structure and spatial distribution differ significantly from bulk soil in wheat crop fields. Soil Biol. Biochem. 113, 275-284. doi: 10.1016/j.soilbio.2017.06.020

Fernández-González, A., Wentzien, N. M., Villadas, P. J., Valverde-Corredor, A., Lasa, A. V., and Gómez-Lama Cabanás, C. (2020). Comparative study of neighboring Holm oak and olive trees-belowground microbial communities subjected to different soil management. PLoS One 15:e0236796. doi: 10.1371/ journal.pone.0236796

Gao, L., Liu, X.-M., Du, Y.-M., Zong, H., and Shen, G.-M. (2019). Effects of tobacco-peanut relay intercropping on soil bacteria community structure. Ann. Microbiol. 69, 1531-1536. doi: 10.1007/s13213-019-01537-9 
Gong, X., Liu, C., Li, J., Luo, Y., Yang, Q., Zhang, W., et al. (2019). Responses of rhizosphere soil properties, enzyme activities and microbial diversity to intercropping patterns on the Loess Plateau of China. Soil Tillage Res. 195:104355. doi: 10.1016/j.still.2019.104355

Gouda, S., Kerry, R. G., Das, G., Paramithiotis, S., Shin, H. S., and Patra, J. K. (2018). Revitalization of plant growth promoting rhizobacteria for sustainable development in agriculture. Microbiol. Res. 206, 131-140. doi: 10.1016/j.micres. 2017.08.016

Gutierrez, T. (2019). "Marine, aerobic hydrocarbon-degrading gammaproteobacteria: overview," in Taxonomy, Genomics and Ecophysiology of Hydrocarbon-Degrading Microbes. Handbook of Hydrocarbon and Lipid Microbiology, ed. T. McGenity (Cham: Springer), 143-152. doi: 10.1007/978-3-030-14796-9_22

Haichar, F. Z., Marol, C., Berge, O., Rangel-Castro, J. I., Prosser, J. I., Balesdent, J. M., et al. (2008). Plant host habitat and root exudates shape soil bacterial community structure. ISME J. 2, 1221-1230. doi: 10.1038/ismej.2008.80

Hamdali, H., Hafidi, M., Virolle, M. J., and Ouhdouch, Y. (2008). Growth promotion and protection against damping-off of wheat by two rock phosphate solubilizing actinomycetes in a P-deficient soil under greenhouse conditions. Appl. Soil Ecol. 40, 510-517. doi: 10.1016/j.apsoil.2008.08.001

Hartman, K., Van Der Heijden, M. G., Wittwer, R. A., Banerjee, S., Walser, J.-C., and Schlaeppi, K. (2018). Cropping practices manipulate abundance patterns of root and soil microbiome members paving the way to smart farming. Microbiome 6, $1-14$.

Heaton, E. A., Dohleman, F. G., and Long, S. P. (2008). Meeting US biofuel goals with less land: the potential of Miscanthus. Glob. Chang. Biol. 14, 2000-2014. doi: 10.1111/j.1365-2486.2008.01662.x

Hernández, E., Baraza, E., Smit, C., Berg, M. P., and Salles, J. F. (2020). Salt Marsh Elevation Drives Root Microbial Composition of the Native Invasive Grass Elytrigia atherica. Microorganisms 8:1619. doi: 10.3390/ microorganisms8101619

Huaizhu, C., Chang, X., Shouzhen, Y., Zudong, S., and Chuying, L. (2004). Breeding of new soybean variety Guizhao 2 (in Chinese). Guangxi Agric. Sci. 35, 153-154.

Huangfu, C., Hui, D., Qi, X., and Li, K. (2019). Plant interactions modulate root litter decomposition and negative plant-soil feedback with an invasive plant. Plant Soil 437, 179-194.

Igiehon, N. O., and Babalola, O. O. (2018). Below-ground-above-ground plantmicrobial interactions: focusing on soybean, rhizobacteria and mycorrhizal fungi. Open Microbiol. J. 12, 261-279. doi: 10.2174/187428580181201 0261

Izquierdo, J. A., and Nüsslein, K. (2006). Distribution of extensive nifH gene diversity across physical soil microenvironments. Microb. Ecol. 51, 441-452. doi: 10.1007/s00248-006-9044-x

Jackson, M. L. (1969). Soil Chemical Analysis-Advanced Course. UW-Madison: Libraries Parallel Press.

Jaiswal, A. K., Elad, Y., Paudel, I., Graber, E. R., Ytryn, E. C., and Frenkel, O. (2017). Linking the Belowground Microbial Composition, Diversity and Activity to Soilborne Disease Suppression and Growth Promotion of Tomato Amended with Biochar. Sci. Rep. 7:44382. doi: 10.1038/srep44382

Khan, M. S., Sadat, S. U., Jan, A., and Munir, I. (2017). Impact of transgenic Brassica napus harboring the antifungal synthetic chitinase $(\mathrm{NiC})$ gene on rhizosphere microbial diversity and enzyme activities. Front. Plant Sci. 8:1307. doi: $10.3389 /$ fpls.2017.01307

Lareen, A., Burton, F., and Schafer, P. (2016). Plant root-microbe communication in shaping root microbiomes. Plant Mol. Biol. 90, 575-587. doi: 10.1007/ s11103-015-0417-8

Lee, S., Hwang, S., Yu, H. J., Oh, D., Yu, J. C., Kim, M. C., et al. (2016). Expression of microRNAs in Horse Plasma and Their Characteristic Nucleotide Composition. PLoS One 11:e0146374. doi: 10.1371/journal.pone.0146374

Li, X., Jousset, A., De Boer, W., Carrión, V. J., Zhang, T., Wang, X., et al. (2019). Legacy of land use history determines reprogramming of plant physiology by soil microbiome. ISME J. 13, 738-751. doi: 10.1038/s41396-018-0300-0

Li, X., Li, X., Zhao, K., Wang, R., and Zhang, X. (2011). Diversity of the rhizosphere soil culture-dependent fungi of mature tobacco. Curr. Res. Microbiol. 2, 9-14.

Li, X., She, Y., Sun, B., Song, H., Zhu, Y., Lv, Y., et al. (2010). Purification and characterization of a cellulase-free, thermostable xylanase from Streptomyces rameus L2001 and its biobleaching effect on wheat straw pulp. Biochem. Eng. J. 52, 71-78. doi: 10.1016/j.bej.2010.07.006

Lian, T., Mu, Y., Ma, Q., Cheng, Y., Gao, R., Cai, Z., et al. (2018). Use of sugarcanesoybean intercropping in acid soil impacts the structure of the soil fungal community. Sci. Rep. 8:14488. doi: 10.1038/s41598-018-32920-2

Liang, Y., Hong, Y., Mai, Z., Zhu, Q., and Guo, L. (2019). Internal and External Microbial Community of the Thitarodes Moth, the Host of Ophiocordyceps sinensis. Microorganisms 7:517. doi: 10.3390/microorganisms7110517

Lisuma, J. B., Zuberi, Z., Ndakidemi, P. A., and Mbega, E. R. (2020). Linking rhizosphere bacterial diversity and soil fertility in tobacco plants under different soil types and cropping pattern in Tanzania: a pilot study. Heliyon 6:e04278. doi: 10.1016/j.heliyon.2020.e04278

Liu, Y., Ponpandian, L. N., Kim, H., Jeon, J., Hwang, B. S., Lee, S. K., et al. (2019). Distribution and diversity of bacterial endophytes from four Pinus species and their efficacy as biocontrol agents for devastating pine wood nematodes. Sci. Rep. 9:12461. doi: 10.1038/s41598-019-48739-4

Lugtenberg, B. J., Malfanova, N., Kamilova, F., and Berg, G. (2013). Plant growth promotion by microbes. Mol. Microb. Ecol. Rhizosphere 2, 561-573.

Luo, S., Yu, L., Liu, Y., Zhang, Y., Yang, W., Li, Z., et al. (2016). Effects of reduced nitrogen input on productivity and $\mathrm{N} 2 \mathrm{O}$ emissions in a sugarcane/soybean intercropping system. Eur. J. Agron. 81, 78-85. doi: 10.1016/j.eja.2016.09.002

Mahakham, W., Sarmah, A. K., Maensiri, S., and Theerakulpisut, P. (2017). Nanopriming technology for enhancing germination and starch metabolism of aged rice seeds using phytosynthesized silver nanoparticles. Sci. Rep. 7:8263. doi: 10.1038/s41598-017-08669-5

Paul, S., and Roychoudhury, A. (2018). "Transgenic plants for improved salinity and drought tolerance," in Biotechnologies of Crop Improvement, eds S. S. Gosal and S. H. Wani (Heidelberg: Springer), 141-181. doi: 10.1007/978-3-31990650-8_7

Peix, A., Mateos, P. F., Rodriguez-Barrueco, C., Martinez-Molina, E., and Velazquez, E. (2001). Growth promotion of common bean (Phaseolus vulgaris L.) by a strain of Burkholderia cepacia under growth chamber conditions. Soil Biol. Biochem. 33, 1927-1935.

Peng, D., Yang, J., Li, J., Xing, Y., Qin, L., Yang, L., et al. (2014). Effects of intercropping with soybean on bacterial and nitrogen-fixing bacterial diversity in the rhizosphere of sugarcane. Chin. J. Plant Ecol. 38, 959-969. doi: 10.3389/ fmicb.2021.713349

Pereira, L. B., Andrade, G. S., Meneghin, S. P., Vicentini, R., and Ottoboni, L. M. (2019). Prospecting plant growth-promoting bacteria isolated from the rhizosphere of sugarcane under drought stress. Curr. Microbiol. 76, 1345-1354. doi: 10.1007/s00284-019-01749-x

Peskett, L., Slater, R., Stevens, C., and Dufey, A. (2007). Biofuels, agriculture and poverty reduction. Nat. Resour. Perspect. 107, 1-6. doi: 10.1098/rstb.2010.0131

Petrosino, J. F., Highlander, S., Luna, R. A., Gibbs, R. A., and Versalovic, J. (2009). Metagenomic pyrosequencing and microbial identification. Clin. Chem. 55, 856-866.

Prodan, A., Tremaroli, V., Brolin, H., Zwinderman, A. H., Nieuwdorp, M., and Levin, E. (2020). Comparing bioinformatic pipelines for microbial $16 \mathrm{~S}$ rRNA amplicon sequencing. PLoS One 15:e0227434. doi: 10.1371/journal.pone. 0227434

R Core Team (2011). R: A Language And Environment For Statistical Computing. Vienna, Austria: R Foundation for Statistical Computing.

Riesenfeld, C. S., Schloss, P. D., and Handelsman, J. (2004). Metagenomics: genomic analysis of microbial communities. Annu. Rev. Genet. 38, 525-552. doi: 10.1146/annurev.genet.38.072902.091216

Santos, L. C., Coelho, R. D., Barbosa, F. S., Leal, D. P., Júnior, E. F. F., Barros, T. H., et al. (2019). Influence of deficit irrigation on accumulation and partitioning of sugarcane biomass under drip irrigation in commercial varieties. Agric. Water Manage. 221, 322-333.

Sasse, J., Martinoia, E., and Northen, T. (2018). Feed your friends: do plant exudates shape the root microbiome? Trends Plant Sci. 23, 25-41. doi: 10.1016/j.tplants. 2017.09.003

Sayer, E. J., Oliver, A. E., Fridley, J. D., Askew, A. P., Mills, R. T., and Grime, J. P. (2017). Links between soil microbial communities and plant traits in a species-rich grassland under long-term climate change. Ecol. Evol. 7, 855-862. doi: $10.1002 /$ ece 3.2700

Schloss, P. D., Westcott, S. L., Ryabin, T., Hall, J. R., Hartmann, M., Hollister, E. B., et al. (2009). Introducing mothur: open-source, platform-independent, 
community-supported software for describing and comparing microbial communities. Appl. Environ. Microbiol. 75, 7537-7541. doi: 10.1128/AEM. 01541-09

Schöler, A., Jacquiod, S., Vestergaard, G., Schulz, S., and Schloter, M. (2017). "Analysis of soil microbial communities based on amplicon sequencing of marker genes. Biol. Fertil. Soils 53, 485-489. doi: 10.1007/s00374-017-1205-1

Sekaran, U., Mccoy, C., Kumar, S., and Subramanian, S. (2019). Soil microbial community structure and enzymatic activity responses to nitrogen management and landscape positions in switchgrass (Panicum virgatum L.). GCB Bioenergy 11, 836-851. doi: 10.1111/gcbb.12591

Sekoai, P. T., Feng, S., Zhou, W., Ngan, W. Y., Pu, Y., Yao, Y., et al. (2020). Insights into the Microbiological Safety of Wooden Cutting Boards Used for Meat Processing in Hong Kong's Wet Markets: a Focus on Food-Contact Surfaces, Cross-Contamination and the Efficacy of Traditional Hygiene Practices. Microorganisms 8:579. doi: 10.3390/microorganisms804 0579

Singh, S., Singh, P., Rai, R., and Pathak, A. (2018). Vegetables intercropping with autumn planted sugarcane. Indian Farming 68, 65-68. doi: 10.1007/s10661015-4451-4

Solanki, M. K., Wang, Z., Wang, F.-Y., Li, C.-N., Lan, T.-J., Singh, R. K., et al. (2017). Intercropping in sugarcane cultivation influenced the soil properties and enhanced the diversity of vital diazotrophic bacteria. Sugar Tech 19, 136-147. doi: 10.1007/s12355-016-0445-y

Soon, Y., and Abboud, S. (1991). A comparison of some methods for soil organic carbon determination. Commun. Soil Sci. Plant Anal. 22, 943-954. doi: 10.1080/ 00103629109368465

Souza, R. D., Ambrosini, A., and Passaglia, L. M. (2015). Plant growth-promoting bacteria as inoculants in agricultural soils. Genet. Mol. Biol. 38, 401-419. doi: 10.1590/s1415-475738420150053

Sun, L., Han, X., Li, J., Zhao, Z., Liu, Y., Xi, Q., et al. (2020). Microbial community and its association with physicochemical factors during compost bedding for dairy cows. Front. Microbiol. 11:254. doi: 10.3389/fmicb.2020.00254

Tai, V., James, E. R., Nalepa, C. A., Scheffrahn, R. H., Perlman, S. J., and Keeling, P. J. (2015). The role of host phylogeny varies in shaping microbial diversity in the hindguts of lower termites. Appl. Environ. Microbiol. 81, 1059-1070. doi: 10.1128/AEM.02945-14

Tai, X., Li, R., Zhang, B., Yu, H., Kong, X., Bai, Z., et al. (2020). Pollution Gradients Altered the Bacterial Community Composition and Stochastic Process of Rural Polluted Ponds. Microorganisms 8:311. doi: 10.3390/microorganisms 8020311

Tew, T. L., and Cobill, R. M. (2008). "Genetic improvement of sugarcane (Saccharum spp.) as an energy crop," in Genetic improvement of bioenergy crops, ed. W. Vermerris (New York, NY: Springer), 273-294. doi: 10.1007/978-0-38770805-8_9

Trabelsi, D., and Mhamdi, R. (2013). Microbial inoculants and their impact on soil microbial communities: a review. Biomed Res. Int. 2013:863240.

Tsukanova, K., Meyer, J., and Bibikova, T. (2017). Effect of plant growth-promoting Rhizobacteria on plant hormone homeostasis. S. Afr. J. Bot. 113, 91-102. doi: 10.1016/j.sajb.2017.07.007

Wang, G. Z., Li, H. G., Christie, P., Zhang, F. S., Zhang, J. L., and Bever, J. D. (2017). Plant-soil feedback contributes to intercropping overyielding by reducing the negative effect of take-all on wheat and compensating the growth of faba bean. Plant Soil 415, 1-12. doi: 10.1007/s11104-016-3139-z

Wang, X., Feng, Y., Yu, L., Shu, Y., Tan, F., Gou, Y., et al. (2020). Sugarcane/soybean intercropping with reduced nitrogen input improves crop productivity and reduces carbon footprint in China. Sci. Total Environ. 719:137517. doi: 10.1016/ j.scitotenv.2020.137517

Wei, H., Movahedi, A., Peijun, Z., Xu, C., Sun, W., Li, D., et al. (2020). Effects of Field-Grown Transgenic Cry1Ah1 Poplar on the Rhizosphere Microbiome. Plant Biotechnol. [preprint]. doi: 10.21203/rs.3.rs-78068/v1

Xu, Y., Lei, B., and Tang, Y. (2018). Effects of Wheat-Faba Bean Intercropping on Soil Microbial Community Structure in the Rhizosphere. Agric. Sci. 9, 1389-1400. doi: 10.4236/as.2018.911096

Yadav, A. N., Verma, P., Kumar, S., Kumar, V., Kumar, M., Sugitha, T. C. K., et al. (2018). "Actinobacteria from rhizosphere: molecular diversity, distributions, and potential biotechnological applications," in New And Future Developments
In Microbial Biotechnology And Bioengineering, eds B. Singh, V. Gupta, and A. Passari (Amsterdam: Elsevier), 13-41.

Yu, H., Chen, S., Zhang, X., Zhou, X., and Wu, F. (2019). Rhizosphere bacterial community in watermelon-wheat intercropping was more stable than in watermelon monoculture system under Fusarium oxysporum f. sp. niveum invasion. Plant Soil 445, 369-381. doi: 10.1007/s11104-01904321-5

Zancarini, A., Lépinay, C., Burstin, J., Duc, G., Lemanceau, P., and Moreau, D. (2013). Combining Molecular Microbial Ecology with Ecophysiology and Plant Genetics for a Better Understanding of Plant-Microbial Communities' Interactions in the Rhizosphere. Mol. Microb. Ecol. Rhizosphere 1, 69-86. doi: 10.1002/9781118297674.ch7

Zhang, C., Liu, G., Xue, S., and Wang, G. (2016). Soil bacterial community dynamics reflect changes in plant community and soil properties during the secondary succession of abandoned farmland in the Loess Plateau. Soil Biol. Biochem. 97, 40-49. doi: 10.1016/j.soilbio.2016.02.013

Zhang, L., Wang, Y., Wei, L., Wang, Y., Shen, X., and Li, S. (2013). Taibaiella smilacinae gen. nov., sp. nov., an endophytic member of the family Chitinophagaceae isolated from the stem of Smilacina japonica, and emended description of Flavihumibacter petaseus. Int. J. Syst. Evol. Microbiol. 63, 37693776. doi: 10.1099/ijs.0.051607-0

Zhao, N., He, M., Li, L., Cui, S., Hou, M., Wang, L., et al. (2020c). Identification and expression analysis of WRKY gene family under drought stress in peanut (Arachis hypogaea L.). PLoS One 15:e231396. doi: 10.1371/journal.pone. 0231396

Zhao, X., Jiang, Y., Liu, Q., Yang, H., Wang, Z., and Zhang, M. (2020a). Effects of Drought-Tolerant Ea-DREB2B Transgenic Sugarcane on Bacterial Communities in Soil. Front. Microbiol. 11:704. doi: 10.3389/fmicb.2020.0 0704

Zhao, X., Liu, Q., Xie, S., Jiang, Y., Yang, H., Wang, Z., et al. (2020b). Response of Soil Fungal Community to Drought-Resistant Ea-DREB2B Transgenic Sugarcane. Front. Microbiol. 11:562775. doi: 10.3389/fmicb.2020.562775

Zheng, H., Wang, X., Chen, L., Wang, Z., Xia, Y., Zhang, Y., et al. (2018). Enhanced growth of halophyte plants in biochar-amended coastal soil: roles of nutrient availability and rhizosphere microbial modulation. Plant Cell Environ. 41, 517-532. doi: 10.1111/pce.12944

Zhou, Q., Chen, J., Xing, Y., Xie, X., and Wang, L. (2019). Influence of intercropping Chinese milk vetch on the soil microbial community in rhizosphere of rape. Plant Soil 440, 85-96. doi: 10.13287/j.1001-9332.201803. 031

Zhou, Y., Chen, M., Guo, J., Wang, Y., Min, D., Jiang, Q., et al. (2019). Overexpression of the soybean (Glycine max) DRE-binding transcription factor GmDREB1 enhanced drought stress tolerance of transgenic wheat in the field. J. Exp. Bot. 71, 1842-1857.

Zhou, Z., Meng, H., Liu, Y., Gu, J.-D., and Li, M. (2017). Stratified bacterial and archaeal community in mangrove and intertidal wetland mudflats revealed by high throughput 16S rRNA gene sequencing. Front. Microbiol. 8:2148. doi: $10.3389 /$ fmicb. 2017.02148

Conflict of Interest: The authors declare that the research was conducted in the absence of any commercial or financial relationships that could be construed as a potential conflict of interest.

Publisher's Note: All claims expressed in this article are solely those of the authors and do not necessarily represent those of their affiliated organizations, or those of the publisher, the editors and the reviewers. Any product that may be evaluated in this article, or claim that may be made by its manufacturer, is not guaranteed or endorsed by the publisher.

Copyright (c) 2021 Wei, Zhang, Wen, Chen, Xia, Liu and Wang. This is an open-access article distributed under the terms of the Creative Commons Attribution License (CC BY). The use, distribution or reproduction in other forums is permitted, provided the original author(s) and the copyright owner(s) are credited and that the original publication in this journal is cited, in accordance with accepted academic practice. No use, distribution or reproduction is permitted which does not comply with these terms. 